\title{
Studi Deskriptif Adversity Quotient pada Guru PG/TK X Bandung
}

\author{
Ayu Nisyia Nur Azizah*, Temi Damayanti Djamhoer \\ Prodi Psikologi, Fakultas Psikologi, Universitas Islam Bandung, Indonesia. \\ *ayunisyia@gmail.com, temidamayanti@gmail.com
}

\begin{abstract}
One of the formal education is kindergarten. PG/TK X Bandung is one of the regular schools that has several students with Special Needs and toddler students. Teachers are faced with situations where students with special needs often experience tantrums and not taking part in class activities. The teacher should pay more attention to students who have special needs and students who are still toddlers. In addition to students with special needs and students who are toddlers, there are also regular students who often annoy their friends and not obey the rules that the teacher has given. Infrastructure facilities owned by schools are still very limited. Teachers get they salary below standard minimum regional. These conditions cause teachers to be able to face the adversities and obstacles that exist. This research is intended to get the description of Adversity Quotient. The measurement tool used is Stoltz's Adversity Response Profile (ARP) (2000). The result is 60\% of teachers having high Adversity Quotient, called by Climbers and 40\% teachers having moderate Adversity Quotient, called by Campers. It means, teachers are able to face adversities and obstacles that exist in the teaching process at school.
\end{abstract}

\section{Keywords: Adversity Quotient, Teacher, Early Childhood Education.}

\begin{abstract}
Abstrak. Salah satu jalur pendidikan formal yaitu Taman Kanak-Kanak. PG/TK X Bandung merupakan salah satu sekolah reguler yang memiliki beberapa siswa ABK dan memiliki siswa dengan usia batita (Bawah Tiga Tahun). Para guru dihadapkan pada situasi dimana siswa dengan kebutuhan khusus sering mengalami tantrum dan sulit mengikuti kegiatan kelas. Guru harus memberikan perhatian lebih pada siswanya yang memiliki kebutuhan khusus dan siswa yang masih batita. Selain siswa dengan kebutuhan khusus dan siswa yang berusia batita, terdapat juga siswa normal yang sering mengganggu temannya, dan tidak patuh pada aturan yang telah guru berikan. Fasilitas sarana prasarana yang dimiliki sekolah masih sangat terbata. Para guru mendapatkan upah yang masih di bawah UMR dan guru sering mendapatkan upahnya tidak sesuai dengan seharusnya. Kondisi tersebut menyebabkan guru harus mampu menghadapi kesulitan dan hambatan yang ada. Penelitian ini bertujuan untuk mendapatkan gambaran mengenai Adversity Quotient pada guru. Pengukuran pada penelitian ini menggunakan Adversity Response Profile (ARP) dari Paul G. Stoltz (2000). Hasil dari penelitian ini menunjukkan sebanyak 60\% (6 guru) memiliki Adversity Quotient tinggi atau disebut dengan Climbers dan 40\% (4 guru) memiliki Adversity Quotient sedang atau disebut dengan Campers. Artinya, guru mampu menghadapi kesulitan dan hambatan-hambatan yang ada dalam proses mengajar di sekolah.
\end{abstract}

Kata Kunci: Adversity Quotient, Guru, PAUD. 


\section{A. Pendahuluan}

Pendidikan di Indonesia dilaksanakan melalui tiga jalurm yaitu informal, nonformal dan formal, pendidikan formal yaitu pendidikan yang diselenggarakan sekolah pada umumnya yang memiliki jenjang yang jelas di mulai dari taman kanak-kanak (TK), sekolah dasar (SD), sekolah menengah pertama (SMP), sekolah menengah atas (SMA), dan perguruan tinggi. Jenjang pertama dalam pendidikan formal yaitu Taman Kanak-Kanak.

Menurut UU Nomor 20 Tahun 2003 Bab I Pasal 1 Ayat 14, pendidikan anak usia dini adalah suatu upaya pembinaan yang ditujukan kepada anak sejak lahir sampai dengan usia enam tahun yang dilakukan melalui pemberian rangsangan pendidikan untuk membantu pertumbuhan dan perkembangan jasmani dan rohani agar anak memiliki kesiapan dalam memasuki pendidikan lebih lanjut.

PG/TK X merupakan salah satu jalur pendidikan formal bagi anak usia dini dengan rentang usia 1,5 sampai 6 tahun. PG/TK X merupakan salah satu sekolah regular yang menerima siswa dengan berkebutuhan khusus. Keseluruhan jumlah siswa di PG/TK X berjumlah 50 siswa, dan terdapat siswa down syndrome, slow learner, global delay, speech delay, ADHD dan ADHD \& autis. Walaupun mereka memiliki beberapa siswa dengan kebutuhan khusus, namun sekolah tidak menyediakan helper atau guru pendamping.

Berdasarkan wawancara yang telah dilakukan, guru merasa dihadapkan dengan kesulitan-kesulitan dalam mengajar siswanya, terutama siswa dengan kebutuhan khusus. Siswa dengan kebutuhan khusus memerlukan cara yang berbeda dalam penyampaian materi, juga tingkat kesulitan kegiatan yang diberikan di dalam kelas. Dengan terbatasnya fasilitas yang dimiliki sekolah juga menjadikan guru harus membuat sendiri alat peraga atau mencari media lain untuk memberikan pengajaran pada siswa-siswanya. Ketika siswa dengan kebutuhan khusus mengamuk atau tantrum di dalam kelas, guru sering merasa kewalahan untuk menenangkan siswanya yang tantrum, namun mereka juga tetap harus melanjutkan kegiatannya di kelas dengan siswa-siswa yang lain.

Selain harus memberikan perhatian khusus pada siswa-siswanya yang memiliki kebutuhan khusus, para guru juga harus memberikan perhatian khusus pada siswanya dengan rentang usia 1,5 sampai 3 tahun yang masih membutuhkan perhatian ekstra saat mereka bermain di luar kelas. Selain kesulitan dalam menangani siswa berkebutuhan khusus dan siswa PG, guru juga dihadapkan oleh siswa-siswa yang sering memberikan perlakuan berbeda pada temannya yang memiliki kebutuhan khusus, sehingga guru harus terus mengingatkan siswanya untuk tidak membeda-bedakan teman dan tetap mengajak bermain bersama temannya yang memiliki kebutuhan khusus.

Selain itu, guru juga mendapatkan upah yang dirasa tidak sebanding dengan tugas dan tanggungjawab yang guru terima, ditambah lagi pemberian upah yang sering kali terlambat dari waktu yang ada pada aturan sekolah.

Agar para guru dapat menghadapi kesulitan-kesulitan dan hambatan yang ada, maka guru memerlukan kecerdasan dalam menghadapi hambatan, atau disebut juga Adversity Quotient. Stoltz (2005) mengungkapkan Adversity Quotient adalah kecerdasan menghadapi kesulitan atau hambatan dan kemampuan bertahan dalam berbagai kesulitan hidup dan tantangan yang dialami. Adversity Quotient juga merupakan kemampuan individu untuk menggerakkan tujuan hidup ke depan. Stoltz juga menyebutkan Adversity Quotient sebagai penentu kesuksesan seseorang. Adversity Quotient mengukur empat aspek, yaitu aspek control, origin dan ownership, reach dan endurance.

Dari penjelasan di atas maka peneliti tertarik untuk mendapatkan gambaran Adversity Quotient pada para guru yang mengajar di PG/TK X Bandung. 


\section{B. Landasan Teori}

Adversity Quotient (Stoltz, 2005) adalah kecerdasan menghadapi kesulitan atau hambatan dan kemampuan bertahan dalam berbagai kesulitan hidup dan tantangan yang dialami. Adversity Quotient merupakan sikap menginternalisasi keyakinan. Adversity Quotient juga merupakan kemampuan individu untuk menggerakkan tujuan hidup ke depan. Adversity Quotient meramalkan seberapa jauh seseorang mampu bertahan menghadapi kesulitan dan memiliki kemampuan untuk mengatasinya, meramalkan siapa yang mampu mengatasi kesulitan dan siapa yang akan hancur atau gagal, serta meramalkan siapa yang akan menyerah dan siapa yang akan bertahan (Stoltz, 2000).

Paul G. Stoltz (2000), mengemukakan Adversity Quotient seseorang terdiri dari empat dimensi $\mathrm{CO}_{2}$ RE. Dimensi-dimensi $\mathrm{CO}_{2} \mathrm{RE}$ akan menentukan Adversity Quotient keseluruhan seseorang. Empat dimensi tersebut yaitu Control, Origin \& Ownership, Reach dan Endurance. Control atau kendali mempertanyakan seberapa banyak kendali yang seseorang rasakan terhadap sebuah peristiwa yang menimbulkan kesulitan. Kendali berkaitan dengan seberapa besar orang merasa mampu mengendalikan kesulitan-kesulitan yang dihadapinya dan sejauh mana individu merasakan bahwa kendali itu ikut berperan dalam peristiwa yang menimbulkan kesulitan. Origin \& Ownership atau asal usul \& pengakuan mempertanyakan dua hal; Siapa atau apa yang menjadi asal usul kesulitan dan sampai sejauh manakah individu mengakui akibat-akibat kesulitan itu. Origin berkaitan dengan rasa bersalah dan Ownership mencerminkan tanggung jawab. Reach atau jangkauan mempertanyakan sejauh manakah kesulitan akan menjangkau bagian-bagian lain dalam kehidupan seseorang. Endurance atau daya tahan mempertanyakan berapa lamakah kesulitan akan berlangsung dan berapa lamakah penyebab kesulitan itu akan berlangsung.

Dalam Adversity Quotient, terdapat tiga kelompok tingkatan, dimana hal ini melihat dari respon individu tersebut dalam menghadapi setiap kesulitan di berbagai aspek kehidupannya. Paul G. Stoltz (2007), mengemukakan tiga tingkatan tersebut yaitu Quitters, Campers dan Climbers. Quitters adalah orang yang memilih untuk keluar, menghindari kewajiban, mundur, dan berhenti. Mereka menolak kesempatan yang diberikan kepada mereka. Quitters menjalani kehidupan yang tidak terlalu menyenangkan. Mereka meninggalkan impian-impian dan memilih jalan yang mereka anggap lebih datar dan lebih mudah. Berbeda dengan Quitter, Campers sekurang-kurangnya telah menanggapi tantangan dan telah mencapai tingkat tertentu. Para Campers merasa puas dengan mencukupkan diri, dan tidak mau mengembangkan diri. Campers tidak memanfaatkan potensi mereka sepenuhnya campers kurang berhasil dalam belajar, tumbuh, dan berprestasi. Climbers adalah sebutan orang yang seumur hidup membaktikan dirinya pada hidupnya, tanpa menghiraukan latar belakang, keuntungan atau kerugian, nasib buruk atau nasib baik. Climbers sering merasa sangat yakin pada sesuatu yang lebih besar daripada diri mereka. Climbers yakin bahwa segala hal bisa dan akan terlaksana, meskipun orang lain bersikap negatif dan sudah memutuskan bahwa jalannya tidak mungkin ditempuh. 


\section{Hasil Penelitian dan Pembahasan}

Berdasarkan hasil penelitian, didapatkan data mengenai tingkat Adversity Quptient pada guru PG/TK X Bandung, yaitu sebanyak 60\% atau 6 guru termasuk dalam kategori Climbers atau memiliki tingkat Adversity Quotient tinggi, dan sebanyak $40 \%$ atau 4 guru termasuk dalam kategori Campers atau memiliki tingkat Adversity Quotient sedang. Berikut hasil penjabaran dari pengukuran tingkat Adversity Quotient menggunakan Adversity Respon Profile (ARP):

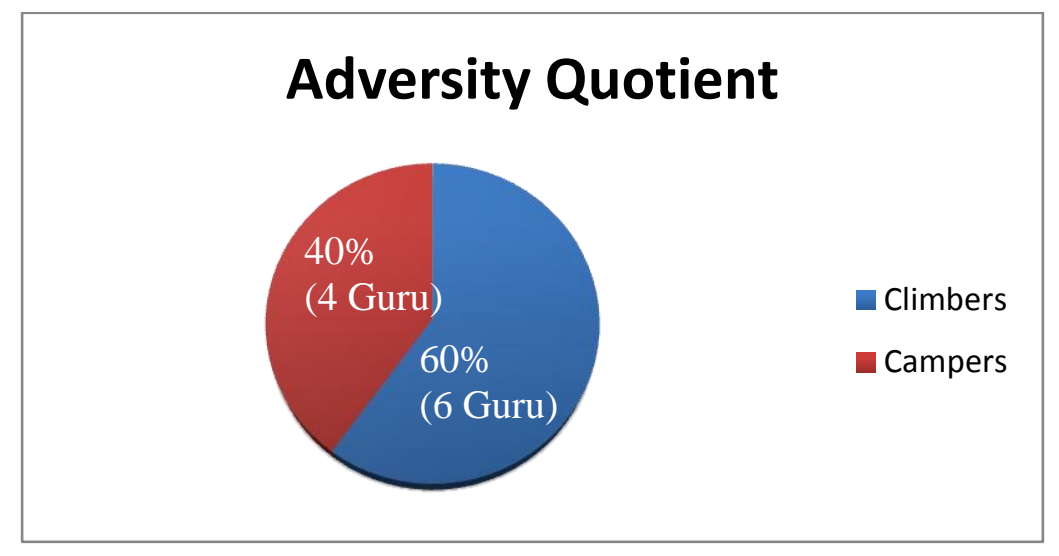

Gambar 1. Hasil Pengukuran Adversity Quotient Guru PG/TK X Bandung

Berdasarkan hasil pengukuran diatas, menunjukkan bahwa sebagian besar guru tergolong dalam kategori Climbers, artinya guru mampu menghadapi kesulitan dan hambatanhambatan yang ada. Stoltz mengungkapkan bahwa seseorang dengan Adversity Quotient tinggi (Climbers) merupakan individu yang merasa berdaya, optimis, tabah, teguh, dan memiliki kemampuan bertahan terhadap kesulitan. Sejalan dengan yang telah diungkapkan oleh Stoltz, para guru tetap bertahan mengajar di PG/TK X Bandung meskipun mereka dihadapkan dengan banyaknya kesulitan dan hambatan yang ada. Para guru terus berjuang untuk menghadapi kesulitan dan hambatan-hambatan yang ada. Para guru tidak mudah menyerah dengan keadaan, dan terus berusaha mencari jalan keluar saat dihadapkan dengan kesulitan dan hambatan-hambatan yang ada, baik dari siswa-siswa yang mereka ajar di PG/TK $\mathrm{X}$, orang tua siswa, dan fasilitas sekolah yang kurang mendukung dalam proses mengajar di PG/TK X Bandung.

Selain para guru yang tergolong dalam kategori Climbers, terdapat juga guru yang tergolong dalam kategori Campers. Menurut Stolts, para Campers merasa puas dengan mencukupkan diri, dan tidak mau mengembangkan diri. Mereka akan bekerja keras dalam hal apapun yang bisa membuat mereka lebih aman dibandingkan dengan yang telah mereka miliki. Mereka masih mengerjakan apa yang harus dikerjakan. Hal ini tercermin dalam perilaku para guru di PG/TK X Bandung yang tergolong dalam kategori Campers. Dalam proses mengajar, para guru yang tergolong dalam kategori Campers menunjukkan sikap inisiatifnya dalam mengelola kelas. Para guru menyampaikan materi kegiatan dengan sungguh-sungguh dan mencari cara agar siswa-siswanya memahami kegiatan yang akan dilakukan, namun ketika mereka dihadapkan dengan siswanya yang memiliki kebutuhan khusus yang tidak mau mengikuti kegiatan yang telah diberikan, mereka tidak terus berusaha membujuk siswanya agar tetap mau mengikuti kegiatan di dalam kelas. 


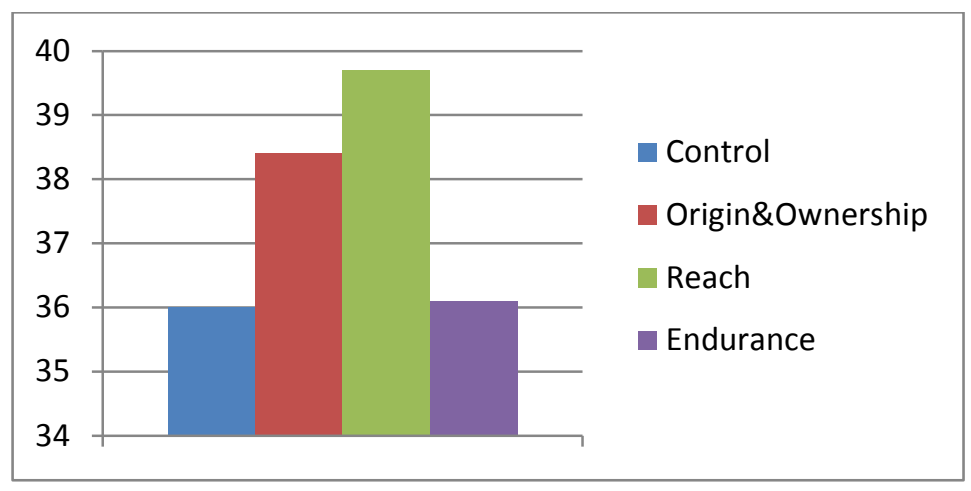

Gambar 2. Penyebaran Skor Rata-Rata Tiap Dimensi Adversity Quotient

Berdasarkan gambar diatas, menunjukkan bahwa skor rata-rata atau mean $(\overline{\mathrm{x}})$ pada dimensi Control yaitu sebesar 36, artinya dimensi Control termasuk dalam kategori sedang. Pada dimensi Origin dan Ownership sebesar 38.4, artinya dimensi Origin dan Ownership termasuk dalam kategori tinggi. Pada dimensi Reach sebesar 39.7, artinya dimensi Reach termasuk dalam kategori tinggi dan pada dimensi Endurance sebesar 36.1, artinya dimensi Endurance termasuk dalam kategori sedang.

\section{Kesimpulan}

Berdasarkan hasil pengolahan data dan pembahasan pada bab sebelumnya, maka dapat ditarik kesimpulan sebagai berikut:

1. Adversity Quotient yang dimiliki sebagian besar guru PG/TK X Bandung termasuk dalam kategori tinggi, sehingga para guru termasuk dalam kategori Climbers.

2. Dilihat dari rata-rata tiap dimensi Adversity Quotient guru PG/TK X Bandung, guru memiliki kategori tinggi pada dimensi Origin dan Ownership dan dimensi Reach.

3. Dilihat dari rata-rata tiap dimensi Adversity Quotient guru PG/TK X Bandung, guru memiliki kategori sedang pada dimensi Control dan dimensi Endurance.

Dari hasil penelitian yang telah dilakukan, saran yang dapat dipertimbangkan diantaranya:

1. Kepada pihak sekolah, agar dapat mengembangkan Adversity Quotient kepada para guru yang masih memiliki Adversity Quotient sedang melalui pelatihan-pelatihan atau seminar.

2. Bagi para guru yang memiliki Adversity Quotient sedang, agar terus meningkatkan tingkat Adveristy Quotientnya. Sebagaimana dalam buku Stoltz, hal tersebut dapat dilakukan dengan cara melatih diri untuk melakukan teknik LEAD (Listen=mendengarkan respons diri terhadap kesulitan; Explore=menjajaki semua asalusul dan pengakuan diri atas akibat kesulitan; Analyze=menganalisis bukti hal-hal tersebut; Do=melakukan sesuatu atau mengambil tindakan untuk menyelesaikan kesulitan) dalam kehidupan sehari-hari.

\section{Daftar Pustaka}

[1] Hurlock,E.B. (1993). Psikologi Perkembangan: Suatu pendekatan sepanjang rentang kehidupan (edisi kelima). Jakarta: Erlangga.

[2] Josephine. Mary. 2015. Adversity Quotient and Teaching Performance of Faculty Members. International Journal of Scientifics and Research Publications, Volume 5, Issue 3

[3] Ningsih, Prayudha S. 2014. Studi deskriptif mengenai adversity quotient pada guru sekolah dasar di SLB-D X Bandung. Skripsi. Universitas Islam Bandung.

[4] Noor, Hasanuddin. (2009). Psikometri (aplikasi dalam penyusunan instrument pengukuran 
perilaku). Bandung: Penerbit Fakultas Psikologi Unisba.

[5] Ronnie, Dani. (2006). The power of emotional and adversity quotient for teachers. Jakarta: Mizan Publika.

[6] Silalahi, Dr. Ulber, MA. (2012). Metode penelitian sosial. Bandung: PT. Refika Aditama.

[7] Stoltz, Paul G. (2007). Adversity quotient: mengubah hambatan menjadi peluang. Jakarta: PT. Grasindo.

[8] Sugiyono. (2012). Metode penelitian kuantitatif kualitatif dan r\&b. Bandung: Alfabeta.

[9] www.jdih.kemenkeu.go.id

[10] www.kelembagaan.ristekdikti.go.id

[11] www.vervalsp.data.kemdikbud.go.id 